\title{
Dynamics of wetlands and their effects on carbon emissions in China coastal region - Case study in Bohai Economic Rim
}

\author{
Lu Qingshui ${ }^{\mathrm{a}, *}$, Gao Zhiqiang ${ }^{\mathrm{a}}$, Zhao Zhiping ${ }^{\mathrm{b}}$, Ning Jicai ${ }^{\mathrm{a}}$, Bi Xiaoli ${ }^{\mathrm{a}}$ \\ a Yantai Institute of Coastal Zone Researches, Chinese Academy of Sciences, Yantai 264003, China \\ ${ }^{\mathrm{b}}$ Chinese Research Academy of Environmental Sciences, Beijing 100012, China
}

\section{A R T I C L E I N F O}

Article history:

Available online 30 November 2013

\begin{abstract}
A B S T R A C T
Wetlands are one of the largest carbon sinks in the world due to their large carbon storage, potential for carbon sequestration in peat formation, sediment deposition and plant biomass. However, rapid economic development is causing changes to wetland carbon storage. China has participated in the implementation of the Kyoto Protocol and is decreasing its carbon emissions. Analyzing the carbon changes that are caused by wetland dynamics may provide some insights regarding decreasing carbon emissions. Therefore, wetland data from 1985, 1995 and 2005 were extracted from remote sensing images. Using spatial analysis and statistics, we determined that the water body area continued to increase, whereas the swamp, floodplain and shallow areas tended to decrease during the period from 1985 to 2005. Those changes caused wetland carbon stock to decrease. The conversion of other land use categories to wetland was the primary cause of carbon stock loss. Therefore, it is more beneficial for China to decrease per capita carbon emissions by decreasing carbon emissions from the conversion of other land use categories to wetlands.
\end{abstract}

(c) 2013 Elsevier Ltd. All rights reserved.

\section{Introduction}

The concentrations of carbon dioxide and other greenhouse gases have increased from 180 to $300-370 \mu \mathrm{l} / \mathrm{l}$, and such an increase has resulted in an increase in the average atmospheric temperature by $0.3-0.6{ }^{\circ} \mathrm{C}$ during the past 100 years (Petit et al., 1999; IPCC, 2007; Vermeer and Rahmstorf, 2009). To reduce the increasing trends of atmospheric temperature, the United Nations Framework Convention on Climate Change and the Kyoto Protocol were implemented to reduce carbon emissions. China's rapid economic development has led to an increase in carbon emissions. As a country that has participated in the implementation of the Kyoto Protocol, rapidly increasing carbon emissions will force China to decrease its carbon emissions by all possible methods in the future.

Wetlands are one of the largest carbon sinks in the world due to their large carbon storage, potential for carbon sequestration in peat formation, sediment deposition and plant biomass. The carbon storage of the terrestrial systems was approximately 560$800 \times 10^{12} \mathrm{~g}$ carbon per year(Tg $\mathrm{C} \mathrm{yr}^{-1}$ ), and $20-25 \%$ of terrestrial carbon(C)was stored in the wetlands (Cai, 2011; McLeod et al., 2011; Hopkinson et al., 2012).However, China rapid economic

\footnotetext{
* Corresponding author. Tel.: +86 05352109192.

E-mail addresses: luqs@Ireis.ac.cn, luqingshui@gmail.com (L. Qingshui).
}

development is causing changes in the coastal wetlands, and such dynamics would further lead to changes in the wetland carbon storage. For example, in coastal areas of China, some coastal wetlands were converted to urban areas, and this process caused carbon release. Simultaneously, some other types of land were changed to shrimp ponds and salt fields, which caused carbon release as well. In contrast, some shallow lands were converted to grasslands or forests, and those changes led to carbon storage changes (Valiela et al., 2001; FAO, 2007; Alphan, 2011; Niu et al., 2012).

The combined effects of those changes on carbon emissions in the coastal wetlands of China remain unclear. Bohai Ring has a higher percentage of coastal wetlands and is experiencing the rapid conversion of wetlands to other land types. Therefore, the Bohai Economic Rim was selected for our study. Remote Sensing (RS) images were used to evaluate the wetland changes, and the Intergovernmental Panel on Climate Change (IPCC) methods were applied to estimate the effects of wetland changes on carbon emissions. The objective of this study was to provide an effective solution for decreasing carbon emissions from coastal wetland changes in China.

\section{Study area}

Bohai Ring, with three provinces and two municipal cities, has a total area of approximately $22340 \mathrm{~km}^{2}$, a total population of 0.23 
billion in 2005 , and is located between $34^{\circ} 23^{\prime}-43^{\circ} 29^{\prime} \mathrm{N}$ and $113^{\circ} 23^{\prime}-$ $125^{\circ} 50^{\prime} \mathrm{E}$ (Fig. 1). The annual average temperature is between 7.7 and $14.4{ }^{\circ} \mathrm{C}$, and the annual average rainfall is between 410 and $965 \mathrm{~mm}$. The major types of wetlands in this area include floodplains and shallow areas, water bodies and swamps. Clay, cinnamon soil, brown earth, and coastal saline soil are the main types of soil in Bohai-Ring, which is in the eastern part of China (National Soil Survey Office, 1993, 1994a, 1994b, 1995a, 1995b, 1996).

\section{Data and methodology}

The period from 1985 to 2005 was selected to study the relation between wetland dynamics and carbon emissions. The wetlands were classified into three categories: water body, swamp, floodplain and shallows. The water body category includes culture ponds, salt fields, reservoirs, lakes and rivers. The wetland spatial data from 1985 to 1995, which were produced from Multi-Spectral Scanner (MSS) and Thematic Mapper (TM) images with visual interpretation, were obtained from the Institute of Geographical Sciences and Natural Resources Research. The wetland spatial data from 2005 were also produced by visual interpretation from TM or Enhanced Thematic Mapper (ETM) images that were recorded in 2005. All TM images were obtained from the United States Geological Survey (USGS) (www.usgs.com). The ancillary data include China \& Brazil Earth Resource Satellite (CBERS) images that were recorded in 2005 and a 1:250 000 terrain map. CBERS images were obtained from the China Center for Resources Satellite Data and Application, and the terrain map was obtained from the Institute of Geographical Sciences and Natural Resources Research. The 1:1000 000 soil spatial data were obtained from the Institute of Geographical Sciences and Natural Resources Research. The data for the soil organic matter, volume-weight and carbon density were obtained from the second general detailed soil survey during the period 1980-1990 (National Soil Survey Office, 1993, 1994a, 1994b, 1995a, 1995b, 1996). The 1:1000 000 spatial data for grasslands were digitalized by our group based on the grassland survey map, which was published by the Ministry of Agriculture of China in 1995. The swamp survey data were obtained from the grassland survey that was published by the Ministry of Agriculture of China in 1995.

The methods that were used in this paper included temporalspatial analysis using the ArcGIS and Intergovernmental Panel on Climate Change (IPCC) methods. ArcGIS temporal-spatial analysis was used to obtain the trends of wetlands during the period from 1985 to 2005. The conversion between wetlands and other land types changed the dynamics of carbon emissions. The IPCC method was selected to quantify the carbon emissions during the process, which was based on the 2006 IPCC Guidelines for National Greenhouse Gas Inventories (IPCC, 2006). The soil organic carbon stock in the 1980s was calculated using the following equation (Equation (1)):

$C_{j}=0.58 * H_{j}^{*} O_{j} * W_{j}$

where, $j$ is the soil type. $C_{j}$ is the carbon stock of $j$ soil type, which is measured in kilogram $(\mathrm{kg}) /$ meter $^{2}\left(\mathrm{~m}^{2}\right) ; H_{j}$ is the soil depth, which is measured in centimeters $(\mathrm{cm}) ; O_{j}$ is the average organic content of $j$ soil type, which is measured in $\%$, and $W_{j}$ is the average bulk density of $j$ soil type, which is measured in gram $(\mathrm{g}) \mathrm{cm}^{-3}$.

There is no peat extraction from peatland in this area, and the carbon emissions from peat extraction are negligible. The carbon emissions from changes between wetlands and other lands were divided into two sections, namely, the conversion from wetlands to other land use categories, and the conversion from other land use categories to flooded land. For the conversion of wetlands to other land use categories, the carbon flux is estimated by adding all the changes in carbon stocks (Equation (2)).

$\Delta C_{w 2 o}=\Delta C_{C}+\Delta C_{W}+\Delta C_{\mathrm{RB}}+\Delta C_{F}+\Delta C_{G}$

where, $\Delta C_{w 20}$ is the carbon flux for the conversion from wetlands to other land use categories, which is measured in tons; $\Delta C_{C}$ is the carbon emissions from the conversion of wetlands to croplands, which is measured in tons; $\Delta C_{W}$ is the carbon emission from the conversion of wetlands to woodlands, which is measured in tons;

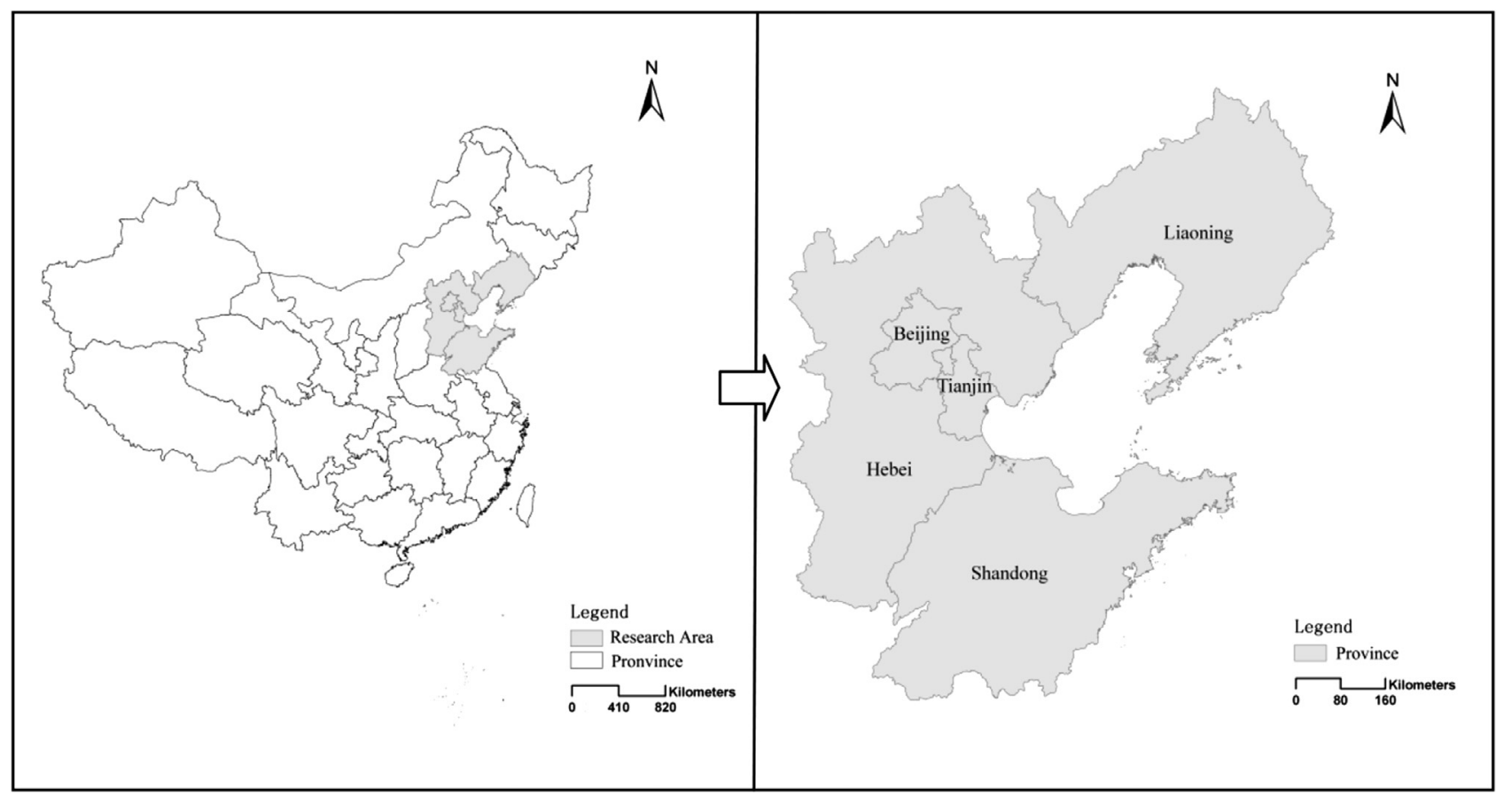

Fig. 1. Location of the study area. 


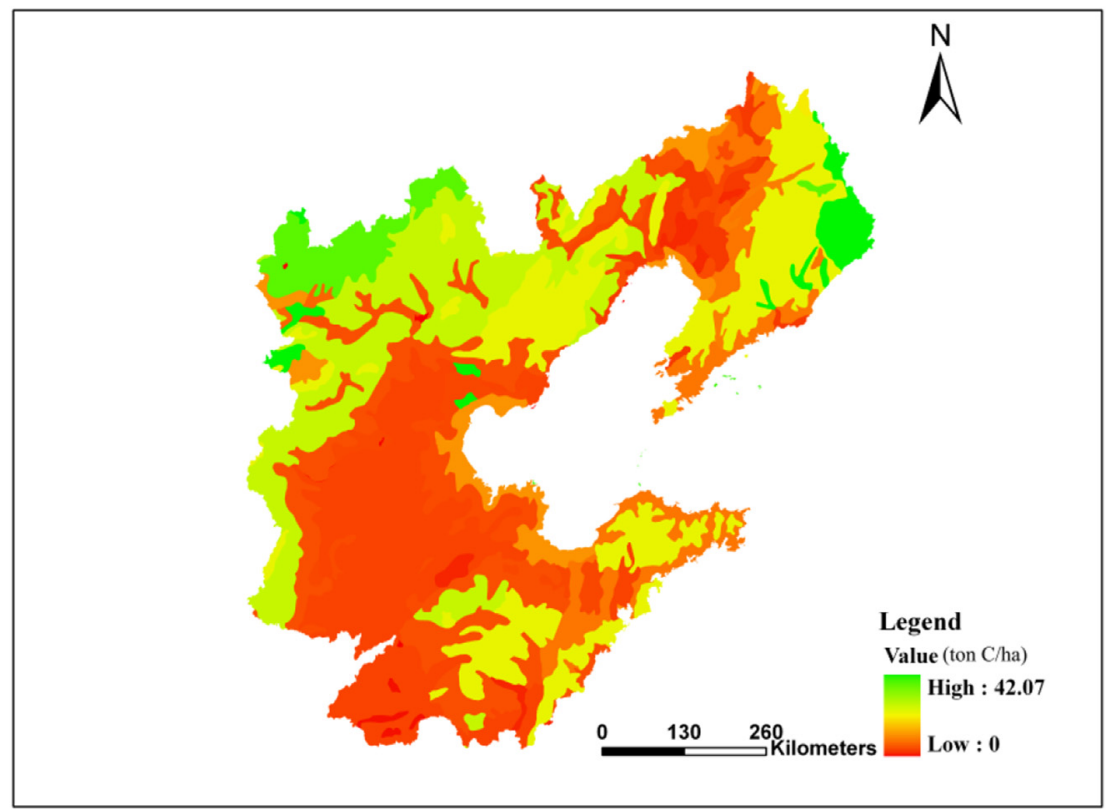

Fig. 2. Referenced soil carbon in Bohai Ring.

$\Delta C_{\mathrm{RB}}$ is the carbon emission from the conversion of water bodies to residential areas and bare land, which is measured in tons; $\Delta C_{F}$ is the carbon emission from the conversion of wetlands to forestry, which is measured in tons; $\Delta C_{G}$ is the carbon emission from the conversion of wetlands to managed grasslands, which is measured in tons.

For the wetlands that are converted to a certain land use category, their carbon emissions are estimated by adding all flux from three carbon pools: biomass, dead organic matter and soil. The carbon stock changes in biomass and dead organic matter are estimated by the following formula (Equation (3)):

$\Delta C_{\text {ot }}=\frac{C_{t_{2}}-C_{t_{1}}}{t_{2}-t_{1}}$

where, $\Delta C_{\text {ot bio }}$ is the annual change in carbon stock in biomass pools, which is measured in tons $C \mathrm{yr}^{-1} ; C_{t_{1}}$ is the carbon stock change in biomass pools at time $t_{1}$, which is measured in ton $C ; C_{t_{2}}$ is the carbon stock change in biomass pools at time $t_{2}$, which is measured in ton $C$. Commonly, the period for $t_{2}-t_{1}$ is 20 years. The values of biomass carbon stocks for swamps are obtained from grassland survey data; the other values for the formula are from IPCC default data.

The carbon stock changes in soil are estimated by the following formulas (Equations (4) and (5)):

$\Delta C_{\text {soil }}=\frac{\left(\mathrm{SOC}_{0}-\mathrm{SOC}_{(0-T)}\right)}{D}$

where, $\Delta C_{\text {soil }}$ is annual change in carbon stocks in soils, which is measured in tons $\mathrm{C} \mathrm{yr}^{-1} ; \mathrm{SOC}_{0}$ is the soil organic carbon stock in the last year of the inventory period, which is measured in tons $C$; SOC $_{(0-T)}$ is the soil organic carbon stock in the beginning of the inventory period, which is measured in tons $C ; T$ is the number of years over a single inventory period, year(yr); $D$ is the period for transition between equilibrium SOC values, which is commonly 20 years.
$\mathrm{SOC}=\sum_{c, s, i}\left(\mathrm{SOC}_{\mathrm{REF}_{c, s, i}} * F_{\mathrm{LU}_{c, s, i}} * F_{\mathrm{MG}_{c, s, i}} * F_{I_{c, s, i}} * A_{c, s, i}\right)$

where, $c$ represents the climate zones, $s$ represents the soil types, $i$ is the set of management systems that are present in this area; $\mathrm{SOC}_{\mathrm{ref}}$ is the reference carbon stock, which is measured in tons $\mathrm{C}$ hectare $^{-1}\left(\mathrm{ha}^{-1}\right) ; \mathrm{F}_{\mathrm{LU}}$ is the stock change factor for land-use systems, dimensionless; $F_{\mathrm{MG}}$ is the stock change factor for the management regime, dimensionless; $F_{I}$ is the stock change factor for the input of organic matter, dimensionless; $A$ is the area of the converted land category, which is measured in hectare(ha). In this paper, $S O C_{R E F}$ is obtained from the second general detailed soil survey (Fig. 2), and the values of other factors are obtained from IPCC recommended data (Table 1 ).

For the conversion of other land use categories to flooded land, carbon emissions are estimated by the following (Equation (6)):

$\Delta C_{\mathrm{FL}}=\Delta C_{\mathrm{CH}_{4}}+\Delta C_{\mathrm{CO}_{2}}$

where, $\Delta C_{\mathrm{FL}}$ represents the carbon emissions from land that was converted to flooded land, which is measured in tons $C \mathrm{yr} ;{ }^{1} \Delta C_{\mathrm{CH}_{4}}$ is the annual carbon emissions through $\mathrm{CH}_{4}$ from land that was converted to flooded land, which is measured in tons $\mathrm{C} \mathrm{yr}^{-1} ; \Delta C_{\mathrm{CO}_{2}}$ is the annual change in the carbon stock in the biomass on land that was converted to flooded land, which is measured in tons $\mathrm{C} \mathrm{yr}^{-1}$.

$\Delta C_{\mathrm{CH}_{4}}$ is estimated by the following equation (Equation (7)):

$\Delta C_{\mathrm{CH}_{4}}=P^{*} E\left(\mathrm{CH}_{4}\right)_{\mathrm{diff}} * A_{\text {flood }_{\text {total }_{\text {surface }}}} * 10^{-3} * \frac{12}{20}$

Table 1

IPCC default values for $F_{\mathrm{LU}}, F_{\mathrm{MG}}$ and $F_{I}$.

\begin{tabular}{llll}
\hline \multirow{2}{*}{ Land use } & \multicolumn{2}{l}{ Factor value type } & \\
\cline { 2 - 4 } & $F_{\mathrm{LU}}$ & $F_{\mathrm{MG}}$ & $F_{I}$ \\
\hline Cropland & 0.8 & 1.02 & 1.04 \\
Swamp & 1 & 1.14 & 1 \\
Grassland & 1 & 1.14 & 1 \\
Resident land & 0.8 & 0.8 & 0.8 \\
Forest land & 1 & 1 & 1 \\
\hline
\end{tabular}


where, $P$ represents the ice-free period, which is measured in days $\mathrm{yr}^{-1} ; \mathrm{E}\left(\mathrm{CH}_{4}\right)_{\text {diff }}$ is the average daily diffusive emission, which is measured in $\mathrm{kg} \mathrm{CH}_{4} \mathrm{ha}^{-1}$ day $^{-1}$; A Alood_total_surface is the total flooded surface area. $\mathrm{E}\left(\mathrm{CH}_{4}\right)_{\text {diff }}$ is $0.09 \mathrm{~kg} /$ day ha. $P$ is 245 days in this region.

$\Delta \mathrm{C}_{\mathrm{CO}_{2}}$ is estimated by the following equation (Equation (8)):

$\Delta C_{\mathrm{CO}_{2}}=\left[\sum_{i} A_{i} *\left(B_{\text {After }}-B_{\text {Before }}\right)\right] * \mathrm{CF}$

where, $A_{i}$ is area of land that is converted annually to flooded land from original land use $i$, which is measured in ha $\mathrm{yr}^{-1} ; B_{\text {After }}$ is the biomass immediately following the conversion to flooded land, which is measured in tons d.m.ha ${ }^{-1}\left(\right.$ default $=0$ ); $B_{\text {Before }}$ is the biomass in land immediately before the conversion to flooded land, which is measured in tons d.m.ha ${ }^{-1}$; CF is the carbon fraction of dry matter, which is measured in tons $C$ (ton. dry matter) ${ }^{-1}$. The biomass for the swamp is from China's national grassland survey data from the late $1980 \mathrm{~s}$, and $\mathrm{CF}$ are 0.5 tons C/ton dry matter for grassland, 0.4 tons $\mathrm{C} /$ ton dry matter for swamp and cropland, 0.48 tons C/ton dry matter for forest, according to IPCC (2006).

\section{Results and analysis}

By visual interpretation, the wetland data from 2005 were obtained from TM/ETM images. The wetland spatial data from 2005 and other data from 1985 to 1995 were combined together, and spatial analysis was performed using the ArcGIS program. The results are shown in Fig. 3 and Tables $2-3$. Those data indicate that the area of water bodies continued to increase, whereas the swamps, floodplains and shallow areas tended to decrease during the period from 1985 to 2005 . The water body area was 866220 ha in 1985 and increased to 1062640 ha in 1995 and 1284287 ha in 2005. In contrast, the area of swamps was 323851 ha in 1985 and decreased to 111936 ha in 1995 and 86179 ha in 2005. The area of floodplains and shallow areas was 739816 ha in 1985, decreased to 696060 ha in 1995, and decreased further to 670704 ha in 2005.

The dynamics of wetlands in this area led to continuous carbon stock loss during the period from 1985 to 2005, and the loss speed tended to decrease for the entire period (Table 3 ). In this area, the wetland carbon stock decreased by 1564060 tons $\mathrm{C} \mathrm{yr}^{-1}$ during the first period from 1985 to 1995 and by 626097.4 tons $C \mathrm{yr}^{-1}$ during the second period from 1995 to 2005 . The conversion of other land use categories to wetland was the main cause of wetland carbon stock loss. Such conversion caused the carbon stock to decrease by 1986978.1 tons $\mathrm{C} \mathrm{yr}^{-1}$ from 1985 to 1995 and by 1012643.2 tons

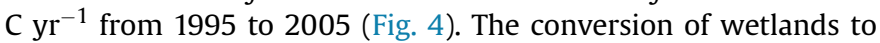
other land use categories caused the carbon stock to increase. However, such an increase was greatly less than the carbon stock decrease from the conversion of other land use categories to wetlands (Fig. 5). To decrease carbon emissions from the conversion of land use categories, the dynamics of the carbon stock in each land use category conversion was further analyzed.

For water bodies, more area of other land use categories was converted to water bodies than that of water bodies that were converted to other land use categories during the entire period (Table 2). This conversion led to the continuous expansion of water bodies. The net changes in the carbon stock during land use category conversions were reflected as carbon emissions, and the emission speed tended to accelerate during the entire period (Table 3). The area of water body conversion to other land use categories was 319432 ha from 1985 to 1995 and 270385 ha from 1995 to 2005. This conversion led to the ecosystem carbon stock increasing by 348431 tons ${\mathrm{C} \mathrm{yr}^{-1}}^{-1}$ during the first period and by
223727.9 tons $\mathrm{C} \mathrm{yr}^{-1}$ during the second period. In contrast, approximately 515852 and 492032 ha of other land use categories was converted to water bodies in the first period and second period, respectively. This conversion caused an ecosystem carbon stock loss of 639625.7 tons $\mathrm{C} \mathrm{yr}^{-1}$ during the first period and 662961.7 tons $\mathrm{C} \mathrm{yr}^{-1}$ during the second period. These conversions caused the net carbon emissions to increase.

One reason for such land use category change is that urban areas are rapidly expanding. To meet the increasing urban demands on water supplies, reservoirs have been continuously built or expanded (Lu et al., 2011). Another reason is that this area is experiencing a phase of rapid urbanization and industrialization. This rapid urbanization and industrialization caused a trade boom in the coastal zone and increased the annual income for the population. These changes led to an increased demand for seafood and other sea products. These factors caused mariculture expansion in this area. Several land use categories were continuously converted to culture ponds or salt fields. This type of land use conversion caused carbon emissions to increase.

Swamps were continuously converted to other land use categories during the entire period from 1985 to 2005, and no other land use categories were converted to swamps (Table 2). Such changes caused continuous carbon stock loss during the entire period (Table 3). Approximately 211915 ha of swamp was converted to other land use categories during the first period from 1985 to 1995, and 25757 ha of swamp was converted to other land use categories during the second period from 1995 to 2005. This conversion led to the ecosystem carbon stock decreasing by 374455.0 tons $\mathrm{C} \mathrm{yr}^{-1}$ during the period from 1985 to 1995 and by 63239.1 tons $C \mathrm{yr}^{-1}$ during the period from 1995 to 2005 . The speed of carbon emissions from this conversion tended to decelerate during the period from 1985 to 2005.

The urbanization and industrialization in China remained at a relatively low level from 1985 to 1995. Maintaining and improving agricultural production was the prior task for the government. The Chinese central government issued many policies to ensure high enough agricultural production to meet the increasing demands. For example, the central government released the "Ten Polices to Further Promote Agricultural Economy Development" in 1985 and the "Guidelines to Strengthen Works in Rural Area" in 1986. These policies encouraged the local people to reclaim some swamps into croplands or other land use categories. With rapid development of economics, swamp protection becomes more and more important for China. China participated in the "Convention on Wetlands of International Importance Especially as Waterfowl Habitat" in 1992, and governments had established a series of natural reserves to protect natural swamps, such as the Yellow River Delta Natural Reserve in 1992 and the Beidagang Wetland Nature Reserve in Tianjin in 2001 (Wang et al., 2011; Xie et al., 2011). Swamp protection laws have also been drafted. Those laws curbed the conversion of swamps to other land use categories.

For shallow areas and floodplains, some were converted to forests, grasslands, water bodies or urban areas. Although water body dynamics also caused the conversion of other land use categories to floodplains, the area of shallows and floodplains still tended to decrease, and this trend caused carbon sinks (Tables 2 and 3). The areas of shallow areas and floodplains conversion to other land use categories during the period from 1985 to 1995 and the period from 1995 to 2005 were 365172 ha and 269705 ha, respectively. These conversions led to the carbon stock increasing by 448942.5 tons $\mathrm{C} \mathrm{yr}^{-1}$ from 1985 to 1995 and by 226057.0 tons $\mathrm{C} \mathrm{yr}^{-1}$ from 1995 to 2005 . The areas of conversion of other land use categories to shallow areas and floodplains during the first and second periods were 311416 ha and 244349 ha, respectively. These conversions caused carbon stocks to decrease by 1347352.4 tons 


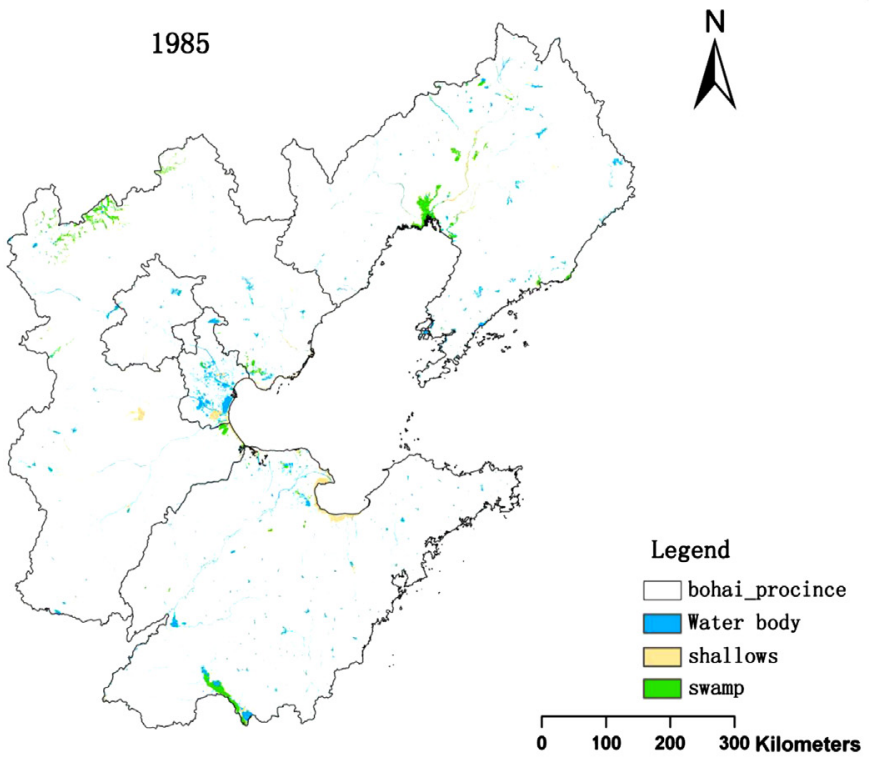

A

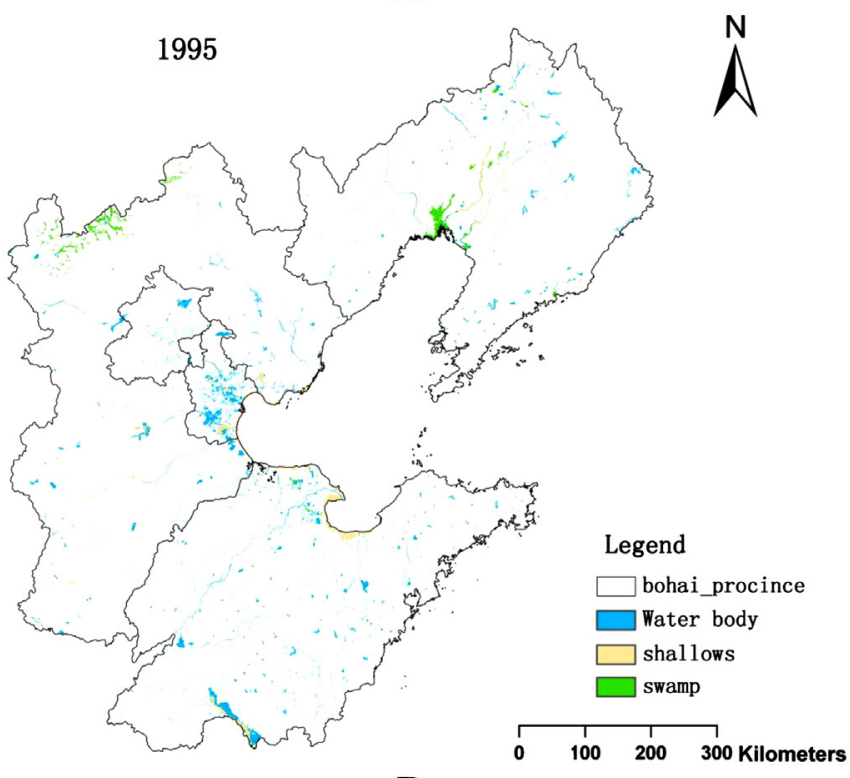

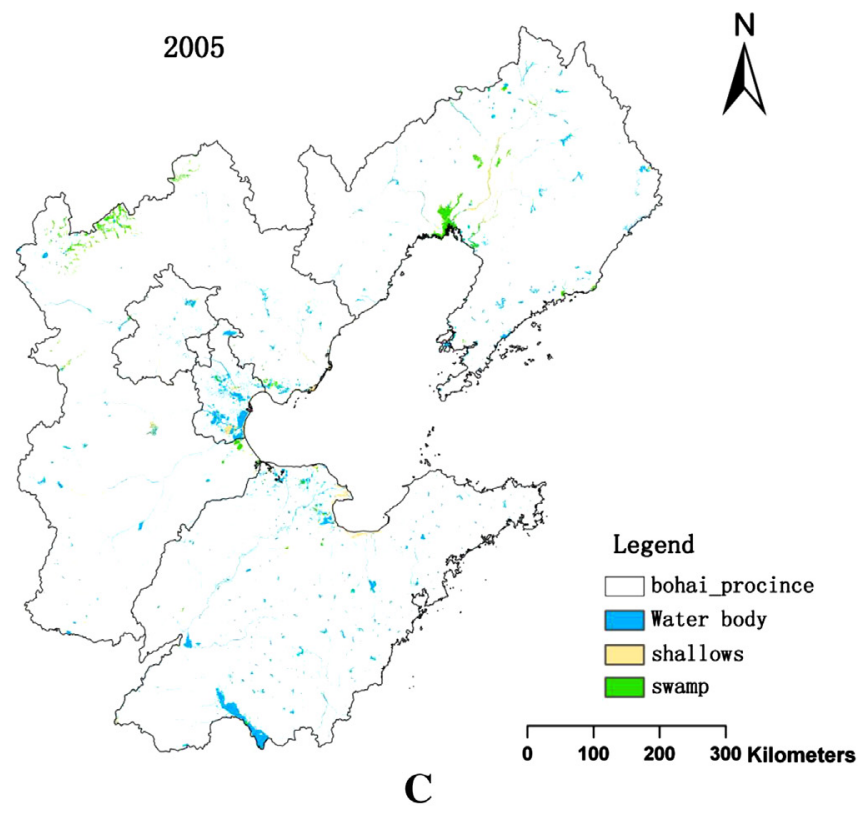

C

Fig. 3. Wetland changes from 1985 to 2005:A, 1985; B, 1995; C, 2005.

$\mathrm{C} \mathrm{yr}^{-1}$ from 1985 to 1995 and by 349681.5 tons $\mathrm{C} \mathrm{yr}^{-1}$ from 1995 to 2005.

Some shallow areas or floodplains were changed into culture ponds or salt fields by farmers to increase their incomes and to meet the demands for seafood and other aquatic products. Excessive reclamation occurred in some areas, and this reclamation caused serious coastal erosion and economic damage. Then, China participated in the Convention on Wetlands in 1992 and enacted some laws to regulate floodplain and shallow area reclamation, such as the Regulations of River Navigation Administration in 1987, the Action Plan for Wetland Protection in 1995, and the Law of Land Administration in 1997. Chinese governments also launched a series of projects to protect coastal erosion, such as a shelterbelt project in 1991.

Table 2

Wetland changes from 1985 to 2005.

\begin{tabular}{|c|c|c|c|c|c|c|c|}
\hline & \multicolumn{2}{|c|}{$\begin{array}{l}\text { Conversion of wetland to other } \\
\text { land use categories(ha) }\end{array}$} & \multicolumn{2}{|c|}{$\begin{array}{l}\text { Conversion of other land use } \\
\text { categories to wetland(ha) }\end{array}$} & \multicolumn{3}{|c|}{ Wetland (ha) } \\
\hline & 1985-1995 & 1995-2005 & 1985-1995 & 1995-2005 & 1985 & 1995 & 2005 \\
\hline Swamps & 211915 & 25757 & 0 & 0 & 323851 & 111936 & 86179 \\
\hline Water bodies & 319432 & 270385 & 515852 & 492032 & 866220 & 1062640 & 1284287 \\
\hline Shallows \& floodplains & 365172 & 269705 & 311416 & 244349 & 739816 & 696060 & 670704 \\
\hline
\end{tabular}


Table 3

Carbon stock changes for wetlands.

\begin{tabular}{|c|c|c|c|c|c|c|}
\hline \multirow[t]{2}{*}{ Wetland } & \multicolumn{2}{|c|}{$\begin{array}{l}\text { Conversion of wetland to other } \\
\text { land use categories(tons/yr) }\end{array}$} & \multicolumn{2}{|c|}{$\begin{array}{l}\text { Conversion of other land use } \\
\text { categories to wetland(tons/yr) }\end{array}$} & \multicolumn{2}{|l|}{ Sum(tons/yr) } \\
\hline & 1985-1995 & 1995-2005 & 1985-1995 & 1995-2005 & 1985-1995 & 1995-2005 \\
\hline Swamps & -374455.0 & -63239.1 & 0 & 0 & -374455 & -63239.1 \\
\hline Water bodies & 348431.0 & 223727.9 & -639625.7 & -662961.7 & -291195 & -439233.8 \\
\hline Shallows \& floodplains & 448942.5 & 226057.0 & -1347352.4 & -349681.5 & -898410 & -123624.5 \\
\hline Total & - & - & - & - & -1564060 & -626097.4 \\
\hline
\end{tabular}

Note: minus value means carbon stock decrease.

\section{Discussion}

Approximately 1.9 billion tons of carbon was released from fossil-fuel use and cement production in China in 2008 (Boden et al., 2011). The per capita emission rate in China was 1.43 tons of carbon, and which exceeded the global average (1.27 metric tons of carbon). The Kyoto target for carbon emission reductions from 2008 to 2012 was 8\% and 6\% for the European Union and Japan, respectively (UNFCCC, 1998). Per capita carbon emissions from wetland dynamics in this region equaled $0.5 \%$ and $0.2 \%$ of carbon emission from fossil fuel use and cement production from 1985 to 1995 and from 1995 to 2005, respectively (Table 4). Therefore, it is more beneficial for China to decrease carbon emissions from fossil fuel use by decreasing carbon emissions that are due to the conversion of other land use types to wetlands or water bodies to other land use types. Currently, this method is a possible way to decrease carbon emissions by regulating the conversion rate of other land use types to wetlands.

The dynamics of wetland and carbon emissions in the coastal areas of China were closely related to policy and administration adjustments. The Chinese economy remained at a relatively low level from 1985 to 1995. Maintaining and improving agricultural production was the prior task for governments. Although the Chinese Constitution stipulates that the wetlands are owned by the State or rural collectives, there are no agencies or laws to regulate wetland reclamation. Many swamps were converted to arable lands, pastures or forests by farmers to increase their incomes. Then, China participated in the Convention of Wetland in 1992. After this convention, several wetland natural reserves have been established to prevent the decrease in swamp areas, such as the Yellow River Delta National Nature Reserve, the Binzhou National Wetland Reserve, the Shuangtai River Mouth National Nature Reserve, and so on. The area of swamps that were converted to other land use categories tended to decrease from 1995 to 2005,

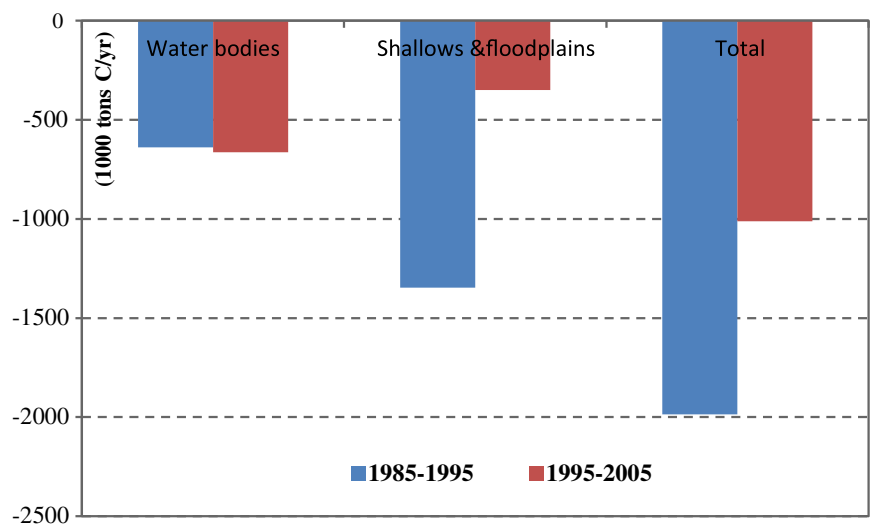

Fig. 4. Carbon stock changes from the conversion of other land use categories to wetlands. (minus value indicates carbon emissions). and this reduction in conversion helped to decrease carbon emissions from swamps.

The conversion of shallow areas to other land use categories could sequestrate carbon from the atmosphere and accelerate economic development. In the 1980s, governments encouraged the reclamation of shallow areas. The central government only made the guideline that the individual who reclaims the shallow area is the one who benefits from that land. Local governments further issued some stipulations to support reclamation. For example, the Hebei Province Government issued a proposed regulation to freely distribute the rights of use certificate for the reclaimed shallow areas, as well as shallow areas to be claimed, and withdraw the certificate for the shallow areas that had permission but did not reclaim after two years. The Liaoning Province Government suggested banks, research agencies and others to provide help for shallow area reclamation. With the assistance of provincial

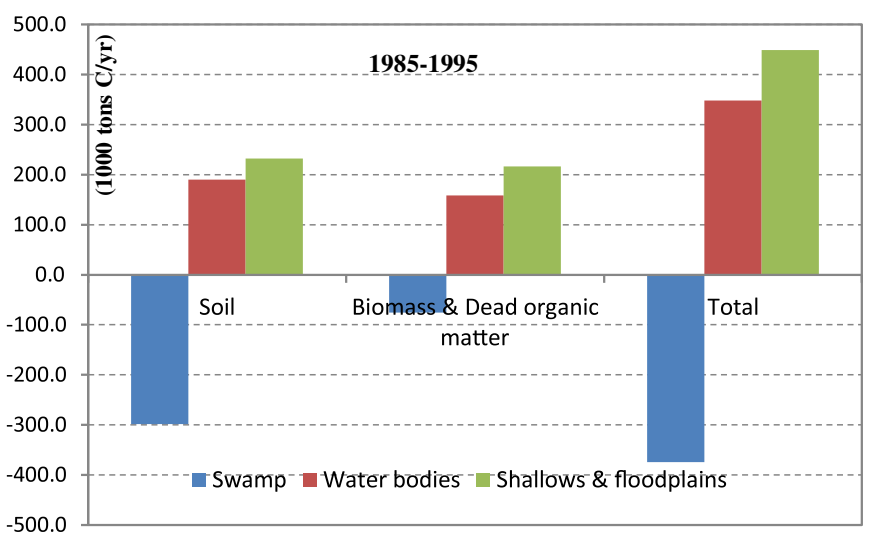

A

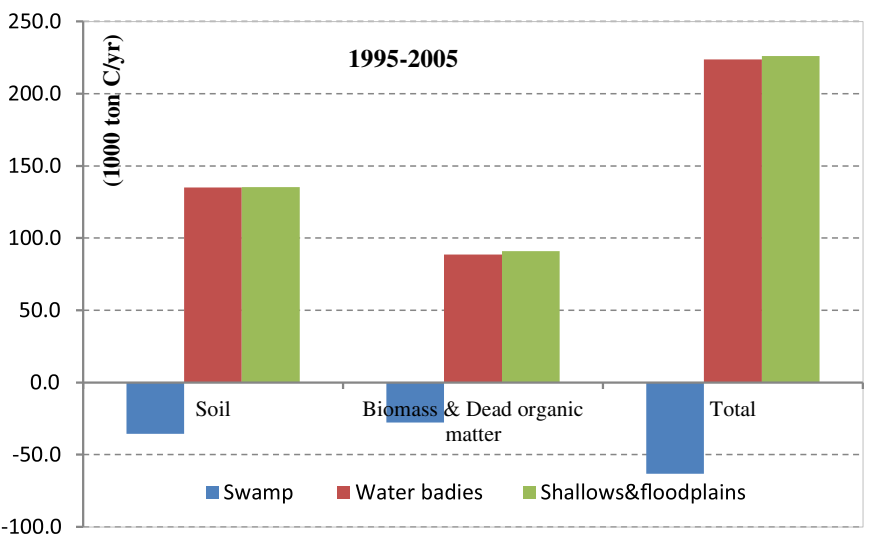

B

Fig. 5. Carbon stock changes from the conversion of wetland to other land use categories: A 1985-1995; B 1995-2005 (minus value indicates carbon emissions). 
Table 4

Carbon emissions from wetland dynamics and that from fossil-fuel use and cement production in Bohai Economic Rim.

\begin{tabular}{|c|c|c|c|c|}
\hline \multicolumn{2}{|c|}{$\begin{array}{l}\text { Carbon emission from } \\
\text { wetland dynamics } \\
\text { (tons } C \mathrm{yr}^{-1} \text { ) }\end{array}$} & \multirow{2}{*}{$\begin{array}{l}\text { Population } \\
\text { (billion) } \\
\\
2005\end{array}$} & \multicolumn{2}{|c|}{$\begin{array}{l}\text { Percent of per capita carbon } \\
\text { emission from wetland } \\
\text { dynamics to that from } \\
\text { fossil-fuel use\& cement } \\
\text { production }(\%)\end{array}$} \\
\hline 1985-1995 & 1995-2005 & & 1985-1995 & 1995-2005 \\
\hline-1564060 & -626097 & 0.23 & 0.5 & 0.2 \\
\hline
\end{tabular}

Note: minus value means carbon stock decrease.

governments, many shallow areas were changed into croplands, forests, culture ponds or other land use categories.

Rapid shallow area reclamation increased carbon stock and caused the shrinkage of bird habitats and other problems. Therefore, governments began to regulate shallow area reclamation by making shallow area reclamation planning and strengthening the administration in the 1990s. At the national level, the planning and administration of the conversion of shallow areas to culture ponds was implemented by the Ministry of Agriculture. The planning and administration of the conversion of shallows to croplands was implemented by the National Bureau of Land. The planning and administration of the conversion of shallow areas to inland water bodies was the task of the Ministry of Water Resources. Environmental problems were administered by the Ministry of Environmental Protection. Local agencies work under the leadership of national ministries. Those agencies caused the conversion of wetlands to other land use categories to decelerate. However, plans made by different agencies were not compatible, and their administration was weakened. Therefore, central governments continued to adjust the tasks among different agencies. The possible effects of those adjustments on wetland dynamics and carbon emission remained unknown, and further studies should be continued. Decreasing carbon emissions could help curb global warming; however, its ecological effects, such as bird habitats, should also be considered in future planning.

\section{Conclusions}

Wetlands from 1985, 1995 and 2005, were extracted from remote sensing images, and IPCC methods were used to analyze the effects of wetland dynamics on carbon emissions in coastal areas of China. Using statistical and spatial analysis, we determined that the water body area continued to increase, whereas the swamps, floodplains and shallow areas tended to decrease during the period from 1985 to 2005 . Those changes caused wetland carbon stocks to decrease during the entire period from 1985 to 2005. For dynamics between wetlands and other land use categories, the decrease in the swamp area and the conversion of other land categories to wetlands led to decreases in the ecosystem carbon stock. In contrast, shallow and floodplain conversions to other land use categories led to increases in the carbon stock. Such dynamics of wetlands and carbon emissions in coastal areas of China were closely related to policies and government administration. To decrease carbon emissions from ecosystems and maintain ecological functions, governments should make new policies to decrease the conversion of other land use categories to wetlands in coastal zone.

\section{Acknowledgments}

We thank Professor Liu Jiyuan for providing the land use/land cover data from 2000. This study was supported by the National Natural Science Foundation of China (41071278,41171334 and 41301596), the Talent fund of the Yantai Institute of Coastal Zone Research, the Ecological Innovation \& Breeding Project (Y254021031), and the Science and Technology Project of Yantai (2012132). Thank you for your support.

\section{References}

Alphan, H., 2011. Classifying land cover conversions in coastal wetlands in the Mediterranean: pairwise comparisons of landsat images. Land Degrad. Dev. 23 (3), 278-292.

Boden, T.A., Marland, G., Andres, R.J., 2011. Global, Regional, and National Fossil-fuel $\mathrm{CO}_{2}$ Emissions. Carbon Dioxide Information Analysis Center, Oak Ridge National Laboratory, U.S. Department of Energy, Oak Ridge, Tenn., U.S.A. http:// dx.doi.org/10.3334/CDIAC/00001_V2011.

Cai, W.J., 2011. Estuarine and coastal ocean carbon paradox: $\mathrm{CO}_{2}$ sinks or sites of terrestrial carbon incineration? Annu. Rev. Mar. Sci. 2011 (3), 123-145.

FAO, 2007. The World's Mangroves 1980-2005. FAO, Rome, Italy.

Hopkinson, C.S., Cai, W.J., Hu, X.P., 2012. Carbon sequestration in wetland dominated coastal systems - a global sink of rapidly diminishing magnitude. Curr. Opin. Env. Sust. 4 (2), 186-194.

IPCC Working Group II, 2007. Contribution to the intergovernmental panel on climate change fourth assessment report. In: Climate Change 2007: Impacts, Adaptation and Vulnerability.

IPCC, 2006. In: Eggleston, H.S., Buendia, L., Miwa, K., Ngara, T., Tanabe, K. (Eds.), 2006 IPCC Guidelines for National Greenhouse Gas Inventories. IGES, Japan. Prepared by the National Greenhouse Gas Inventories Programme.

Lu, Q.S., Liang, F.Y., Bi, X.L., Duffy, R., Zhao, Z.P., 2011. Effects of urbanization and industrialization on agricultural land use in Shandong Peninsula. Ecol. Indic. 11 (6), 1710-1714.

McLeod, E., Chmura, G.L., Bouillon, S., Salm, R., Björk, M., Duarte, C.M., Lovelock, C.E., Schlesinger, W.H., Silliman, B.R., 2011. A blueprint for blue carbon: toward an improved understanding of the role of vegetated coastal habitats in sequestering $\mathrm{CO}_{2}$. Front. Ecol. Environ. 9 (10), 552-560.

National Soil Survey Office, 1993. Soil Species of China, vol. I. Chinese Agriculture Press, Beijing.

National Soil Survey Office, 1994a. Soil Species of China, vol. II. Chinese Agriculture Press, Beijing.

National Soil Survey Office, 1994b. Soil Species of China, vol. III. Chinese Agriculture Press, Beijing.

National Soil Survey Office, 1995a. Soil Species of China, vol. IV. Chinese Agriculture Press, Beijing.

National Soil Survey Office, 1995b. Soil Species of China, vol. V. Chinese Agriculture Press, Beijing.

National Soil Survey Office, 1996. Soil Species of China, vol. VI. Chinese Agriculture Press, Beijing.

Niu, Z.G., Zhang, H.Y., Wang, X.W., Yao, W.B., Zhou, D.M., Zhao, K.Y., 2012. Mapping wetland changes in China between 1978 and 2008. Chin Sci. Bull. 57 (22), 2813-2823.

Petit, J.R., Jouzel, J., Raynaud, D., et al., 1999. Climate and atmospheric history of the past 420000 years from the Vostok ice core, Antarctic. Nature 399, 429-436.

United Nations Framework Convention on Climate Change (UNFCCC), 1998. Kyoto Protocol.

Valiela, I., Bowen, J.L., York, J.K., 2001. Mangrove forests: one of the world's threatened major tropical environments. Bioscience 51 (10), 807-815.

Vermeer, M., Rahmstorf, S., 2009. Global sea level linked to global temperature. Proc. Natl. Acad. Sci. USA 106, 21527-21532.

Wang, C.Y., Wang, W.C., He, S.J., Du, J.G., Sun, Z.G., 2011. Sources and distribution of aliphatic and polycyclic aromatic hydrocarbons in Yellow River Delta Nature Reserve, China. Appl. Geochem. 26 (8), 1330-1336.

Xie, Z., Liu, J., Zhu, G., Shao, Q., Xu, X., 2011. Evaluating habitat change and boundary adjustment of a Nature reserve in coastal wetlands: case study of Beidagang nature reserve, China. J. Coastal Res. 27 (5), 966-972. 